\title{
Comorbidities of migraine
}

\author{
Shuu-Jiun Wang ${ }^{1,2}$, Ping-Kun Chen ${ }^{3,4}$ and Jong-Ling Fuh ${ }^{1,2}$ \\ 1 Department of Neurology, Neurological Institute, Taipei Veterans General Hospital, Taipei, Taiwan \\ 2 National Yang-Ming University School of Medicine, Taipei, Taiwan \\ ${ }^{3}$ Department of Neurology, Lin-Shin Hospital, Taichung, Taiwan \\ ${ }_{4}^{4}$ Graduate Institute of Clinical Medicine Science, China Medical University, Taichung, Taiwan
}

\author{
Edited by: \\ Mario Peres, Instituto Israelita de \\ Ensino e Pesquisa Albert Einstein, \\ Brazil \\ Reviewed by: \\ Giancarlo Luchetti, Centro de Terapia \\ Intensiva, Hospital de Aeronáutica de \\ São Paulo, Brazil \\ Marcelo Valença, Federal University of \\ Pernambuco, Brazil \\ ${ }^{*}$ Correspondence: \\ Shuu-Jiun Wang, Department of \\ Neurology, Neurological Institute, Taipei \\ Veterans General Hospital, Taipei 112. \\ Taiwan \\ e-mail: sjwang@vghtpe.gov.tw
}

Migraine is a common neurological disorder and can be severely disabling during attacks. The highest prevalence occurs between the ages of 25 and 55 years, potentially the most productive period of life. Migraine leads to a burden not only for the individual, but also for the family and society in general. Prior studies have found that migraine occurs together with other illnesses at a greater coincidental rate than is seen in the general population. These occurrences are called "comorbidities," which means that these disorders are interrelated with migraine. To delineate the comorbidities of migraine is important, because it can help improve treatment strategies and the understanding of the possible pathophysiology of migraine. The comorbid illnesses in patients with migraine include stroke, sub-clinical vascular brain lesions, coronary heart disease, hypertension, patent foramen ovale, psychiatric diseases (depression, anxiety, bipolar disorder, panic disorder, and suicide), restless legs syndrome, epilepsy and asthma. In this paper, we review the existing epidemiological and hospital-based studies, and illustrate the connections between these illnesses and migraine.

Keywords: migraine, cerebrovascular disorder, depression, anxiety, comorbidity

\section{INTRODUCTION}

Migraine is one of the most common neurological disorders (Andlin-Sobocki et al., 2005). It causes substantial levels of disability; however, the burden of migraine is underestimated in scope and scale. In most countries, migraine is under-recognized and under-treated (Stewart et al., 1992; Wang et al., 2000).

The term comorbidity is used to refer to the statistical association of two distinct diseases in the same individual at a rate higher than expected by chance (Lipton and Silberstein, 1994). Many illnesses are reported to be comorbid with migraine (Scher et al., 2005a), which stresses the clinical complexity of this headache disorder. Comorbidity in migraine is important from several perspectives: (1) co-occurrence of diseases can complicate the diagnosis, e.g., focal sign of migraine and stroke; (2) one disease can remind the clinicians of the other diseases, e.g., migraine and restless legs syndrome (RLS); (3) one treatment for two diseases, e.g., tricyclic antidepressants for migraine patients with depressive disorders; and (4) comorbidity of illnesses can provide clues to the pathophysiology of migraine.

This review focuses on the findings of common comorbid disorders of migraine, which include stroke, sub-clinical vascular brain lesions, coronary heart disease, hypertension, patent foramen ovale (PFO), psychiatric diseases, RLS, obesity, epilepsy, asthma and other disorders.

\section{COMORBIDITY OF MIGRAINE}

\section{CARDIOVASCULAR DISORDERS (CVD)}

The vascular component of CVD is suspected to be part of the pathophysiology of migraine and led to the therapeutic development of triptans. Many studies delineate the association between migraine and vascular problems. In this section, we focus on the relationship between migraine and stroke, sub-clinical vascular brain lesions, coronary artery disease, hypertension and PFO. Table 1 summarizes the studies of CVD and migraine.

\section{Stroke}

The association between migraine and ischemic stroke has been well known from many case-control and cohort studies. The Atherosclerosis Risk in Communities Study in the United States (Stang et al., 2005) recorded the life-time headache history of participants by using the modified International Headache Society (IHS) diagnostic criteria, and the stroke events were identified and validated using medical records. The results showed migraine with aura was associated with stroke symptoms [odds ratio (OR) 5.46], transient ischemic attack (TIA) symptoms (OR 4.28), and verified ischemic stroke events (OR 2.81). Another important piece of evidence came from a prospective analysis on the risk of ischemic stroke in the Women's Health Study (Kurth et al., 2005). Nearly 40,000 healthy females aged 45 years and older, and without a history of stroke, TIA or an abnormal neurological examination, were followed up for a mean of 9 years. Migraine and aura were based on self-report. In this prospective study, migraine with aura was associated with incidents of ischemic stroke [Hazard ratio (HR) 1.70], with the risks most evident for those under 55 years of age at baseline (HR 2.25). In the subgroup of Women's Health Study (Kurth et al., 2006), after adjustment of the risk factors for major CVD including age, blood pressure, antihypertensive medication, diabetes, body mass index (BMI), smoking, alcohol consumption, menstrual status, hormone levels, oral contraceptive use and cholesterol, active migraine with aura was associated with an increased risk of ischemic stroke. Importantly, women who reported active migraine without aura were not significantly related to an increased 
Table 1 | Summary of the studies of cardiovascular disorders (CVD) and migraine.

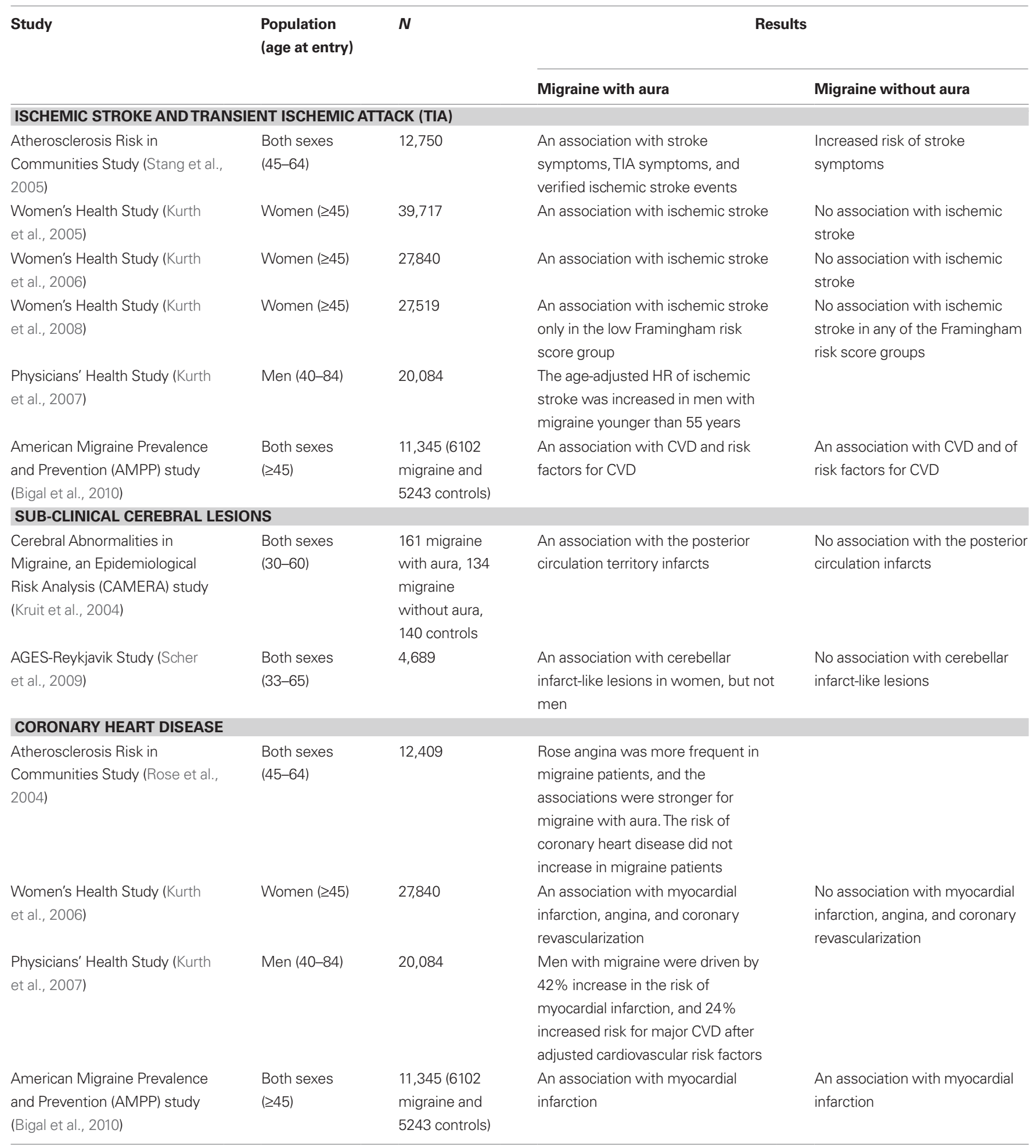

risk of ischemic stroke in this study. Furthermore, a recent report from the same group also showed the association between ischemic stroke and active migraine with aura in women only in the low Framingham risk score group (10-year risk of coronary heart disease < 1\%, HR: 3.88; 95\% CI, 1.87-8.08) (Kurth et al., 2008). In consideration of the individual components of the Framingham risk score, this diametric pattern of association was driven by a particularly increased risk of ischemic stroke among women with active migraine with aura who were young (aged 45-49) and had low total cholesterol concentrations. With regard to men, prospective 
data from the Physicians' Health Study investigated the association between migraine and CVD in men (Kurth et al., 2007). In this study, 20,084 apparently healthy US male physicians aged 40-84 at study entry were followed for a mean of 15.7 years. The age-adjusted HR of ischemic stroke was increased in men with migraine younger than 55 years [relative risk (RR): 1.84; 95\% CI: 1.10-3.08]. This association was not found in older age groups. One recent population-based study [part of the American Migraine Prevalence and Prevention (AMPP) study] found a positive association between migraine with aura and stroke in both adult men and women (Bigal et al., 2010). After adjustment for age, gender, disability, treatment and CVD risk factors, migraine with aura remained significantly associated with stoke (Bigal et al., 2010).

\section{Sub-clinical vascular brain lesions}

Sub-clinical cerebral lesions, especially in the posterior circulation or white matter, were reported to be more frequent in patients with migraine (especially migraine with aura) in a case-controlled MRI study (CAMERA) (Kruit et al., 2004). The same group also demonstrated that most ( $88 \%)$ infratentorial infarct-like lesions had a vascular border zone location in the cerebellum and, further, that a combination of hypoperfusion (possibly migraine attack-related) and embolism is the most likely mechanism for posterior circulation infarction in migraine (Kruit et al., 2005). Recently, MRI was performed in participants of the AGES-Reykjavik Study, more than 26 years after the initial headache diagnosis. Women, but not men, with migraine with aura in midlife were associated with increased cerebellar infarct-like lesions in late life (Scher et al., 2009).

\section{Coronary heart disease}

The association between migraine and coronary artery disease was conflicting in several large scale population-based studies. Of 12,409 participants, the Atherosclerosis Risk in Communities Study evaluated the prevalence of Rose angina and coronary artery disease (Rose et al., 2004). After more than 10 years of follow-up, Rose angina was more frequent in migraine patients, and the associations were stronger for migraine with aura [prevalence ratio (PR):3.0, 95\% CI: 2.4-3.7]. Nevertheless, the risk of coronary heart disease did not increase in migraine patients (Rose et al., 2004). However, in the Women's Health Study (Kurth et al., 2006), not only ischemic stroke, but also other major cardiovascular events, such as myocardial infarction, angina and coronary revascularization, were reported to be related to migraine with aura. In contrast to ischemic stroke, the association between myocardial infarction and active migraine with aura was demonstrated only in those with a high Framingham risk score (10-year risk of coronary heart disease > 10\%, HR: 3.34; 95\% CI, 1.50-7.46), particularly among women with high total cholesterol concentrations (Kurth et al., 2008). In the Physicians' Health Study (Kurth et al., 2007), men with migraine demonstrated a $42 \%$ increase in the risk of myocardial infarction and a $24 \%$ increased risk for major CVD after adjustment for the cardiovascular risk factors. Recently, the AMPP sub-study in adults of both genders showed both migraine with and without aura were associated with myocardial infarction (OR: 2.86 vs. 1.85 , respectively) after adjustment for gender, age, disability, treatment and CVD risk factors (Bigal et al., 2010).

\section{Hypertension and other CVD risk factor}

Reports on the relationship between migraine and hypertension are controversial. The positive association was noted in two clinicbased studies (Franceschi et al., 1997; Cirillo et al., 1999), and no association in one population-based study (Rasmussen and Olesen, 1992). Actually, two prospective population-based studies demonstrated a negative association between migraine and hypertension (Wiehe et al., 2002; Tzourio et al., 2003). The CVD risk factors were recorded in several population-based studies to evaluate the associations between migraine, and stroke or coronary artery disease. The GEM study (Scher et al., 2005b) and AMPP sub-study (Bigal et al., 2010) demonstrated a higher cardiovascular risk profile in migraineurs with higher cholesterol and blood pressure levels. However, this result was not confirmed in the Women's Health Study (Kurth et al., 2006). Further studies are needed to confirm the relationship between blood pressure and other CVD risk factors in migraine patients.

\section{Gene polymorphisms}

Two important gene polymorphisms were studied in both migraine and CVD: the $677 \mathrm{C}>\mathrm{T}$ polymorphism of the methylenetetrahydrofolate reductase (MTHFR) gene, and the D/I polymorphism of the angiotensin-converting enzyme (ACE) gene. The MTHFR $677 \mathrm{C}>\mathrm{T}$ polymorphism was investigated in the Women's Health Study (Schürks et al., 2008). The study found that the 677TT genotype was associated with a $20 \%$ reduced risk for migraine with aura $(\mathrm{RR}=0.79 ; 95 \% \mathrm{CI}, 0.65-0.96 ; p=0.02)$, but was not associated with ischemic stroke or myocardial infarction. However, co-existence of migraine with aura and the 677TT genotype further increases the risk for major CVD $(\mathrm{HR}=3.66$; 95\% CI $=1.69-7.90 ; p=0.001)$. This pattern was only apparent in ischemic stroke $(\mathrm{HR}=4.19$; $95 \% \mathrm{CI}=1.38-12.74 ; p=0.01)$, but not in myocardial infarction $(\mathrm{HR}=2.88 ; 95 \% \mathrm{CI}=0.84-9.88 ; p=0.09)$. The ACE D/I polymorphism was studied in the same cohort (Schürks et al., 2009). There is no association between the ACE D/I polymorphism, and migraine or CVD. However, the risk of CVD was doubled in migraine with aura patients, but only for carriers of the DD/DI genotype. The risk was not increased among carriers of the II genotype. Due to the limited number of outcome events, future studies are warranted to further investigate this association.

\section{Patent foramen ovale (PFO)}

An association between PFO and migraine has been identified in many studies (Del Sette et al., 1998; Anzola et al., 1999; Ferrarini et al., 2005; Schwerzmann et al., 2005; Carod-Artal et al., 2006). It is hypothesized that right-to-left shunts via PFO may allow for paradoxical embolism, and passage of higher concentrations of vasoactive substances into the cerebral arterial system (Buzzi and Moskowitz, 2005; Schwedt and Dodick, 2006). In most studies, PFO is common in patients with migraine with aura (Del Sette et al., 1998; Anzola et al., 1999; Ferrarini et al., 2005; Schwerzmann et al., 2005), and some retrospective studies suggest that $\mathrm{PFO}$ closure is effective for migraine treatment (Post et al., 2004; Schwerzmann et al., 2004). However, several studies reported different results: in a cross-sectional study from the Northern Manhattan Study (NOMAS), 1101 stroke-free precipitants aged $>39$-years old (mean 69 \pm 10 -years old) were 
examined by transthoracic echocardiography for PFO. There was no difference in the prevalence of PFO between participants with and without migraine (Rundek et al., 2008). In the Migraine Intervention with STARFlex Technology (MIST) trial - a prospective, randomized, double-blind trial - the intractable migraine with aura patients with moderate or large right-to-left shunts were included (Dowson et al., 2008). Patients were randomized to receive transcatheter PFO closure with the STARFlex implant or a sham procedure. After a 6-month follow-up, there were no differences in migraine cessation rates between the two groups (primary outcome measures). However, excluding two outliers, the implant group demonstrated a greater reduction in the frequency of migraine attacks. Another study found that people who have migraine with aura are more likely to experience migraine relief following PFO closure than people who have migraine without aura (Jesurum et al., 2008). However, more puzzlingly, migraine relief can occur even if residual shunting occurs after the PFO is closed. A meta-analysis using the system Grades of Recommendation Assessment, Development and Evaluation (GRADE) by Schwedt et al. (2008) showed the evidence was low for the higher prevalence of migraine in PFO patients based on 11 observational studies, and the evidence was low to moderate for the higher prevalence of PFO in migraine patients based on seven observational studies. The efficacy of the closure of PFO in treatment of migraine was still not certain due to the major issue of the unclear definition of "improvement" in most studies (Schwedt et al., 2008).

\section{PSYCHIATRIC DISORDERS}

Psychiatric disorders are frequently comorbid with migraine, and result in a significant burden in patients with migraine including depression, anxiety disorder, bipolar disorder, and suicide ideation and attempt (Table 2).

\section{Depression}

In 1990, a Zürich prospective epidemiological cohort study on young adults aged 27 and 28 years evaluated the prevalence of psychiatric comorbidity in subjects with migraine. This study demonstrated a strong association between migraine and depression $(\mathrm{OR}=2.2)$ (Merikangas et al., 1990). A bidirectional association of migraine and depression were later found in three longitudinal population-based studies (Breslau et al., 1994, 2000, 2003). In these, the risk of new onset migraine in people with depression ranged from 2.8 to 3.5. Conversely, the risk of new onset of depression in people with migraine ranged from 2.4 to 5.8. In another study, which used data from an adult US population to look at the cross-sectional associations between three pain conditions (migraine, arthritis and back pain) and three psychiatric disorders [depression, generalized anxiety disorder (GAD) and panic attacks] (McWilliams et al., 2004), the associations between the three psychiatric disorders were roughly similar. In this population, $28.5 \%$ of the migraine subjects were considered clinically depressed, while only $12.3 \%$ of subjects without migraine fit the same criteria (OR 2.8). Comorbidity with psychological distress was related to a poorer health-related quality of life in patients with migraine (Wang et al., 2001). In a recent study, patients with disabling chronic headache had high frequencies of somatic complaints (OR 8.6) and
Table $\mathbf{2}$ |The odds ratios of comorbid psychiatric disorders in patients with migraine.

\begin{tabular}{|c|c|}
\hline Psychiatric disorders & Odds ratio \\
\hline $\begin{array}{l}\text { Major depression (Merikangas et al., } \\
\text { 1990; Breslau et al., 2003) }\end{array}$ & $2.2-3.14$ \\
\hline $\begin{array}{l}\text { Bipolar spectrum (Merikangas et al., } \\
\text { 1990; Breslau et al., 1991) }\end{array}$ & $2.9-7.3$ \\
\hline Any anxiety (Merikangas et al., 1990) & 2.7 \\
\hline $\begin{array}{l}\text { Panic disorder (Merikangas et al., 1990; } \\
\text { Breslau et al., 2001) }\end{array}$ & $3.0-5.09$ \\
\hline $\begin{array}{l}\text { General anxiety disorder (Merikangas et al., } \\
\text { 1990; McWilliams et al., 2004) }\end{array}$ & $3.9-5.3$ \\
\hline Agoraphobia (Merikangas et al., 1990) & 2.4 \\
\hline Social phobia (Merikangas et al., 1990) & 3.4 \\
\hline Suicide attempt* (Breslau, 1992) & 4.3 \\
\hline $\begin{array}{l}\text { Suicide ideation* (Breslau, 1992; } \\
\text { Wang et al., 2009) }\end{array}$ & $1.79-2.4$ \\
\hline
\end{tabular}

* migraine with aura only.

major depressive disorder (OR 25.1) (Tietjen et al., 2007). We used a 30-item version of the Chinese Health Questionnaire (CHQ-30) to screen minor psychiatric morbidity if the score was $>10$ in a Taiwan population. The study showed that subjects with chronic migraine had a higher chance to have a positive screening result in the CHQ-30 score $(>10)$ than those with chronic tension-type headache (CTTH) (66\% vs. 36\%) (Lu et al., 2001). In clinic-based studies, patients with chronic daily headache, especially chronic migraine, had high frequencies of major depression and panic disorders (Juang et al., 2000). In addition, the presence of major depression was a poor outcome predictor in patients with chronic daily headache $(\mathrm{RR}=1.8)$ (Lu et al., 2000).

\section{Generalized anxiety disorder}

The association between anxiety and migraine was noted in both clinic and community-based studies (Merikangas et al., 1990; Breslau et al., 1991; Smoller et al., 2003; McWilliams et al., 2004). The study conducted by McWilliams and his colleagues also showed the association between migraine and anxiety: $9.1 \%$ of subjects with migraine have $\mathrm{GAD}$, compared to $2.5 \%$ of those without migraine $(\mathrm{OR}=3.9)$ (McWilliams et al., 2004). In the epidemiology cohort study in Zurich, the prevalence of GAD was high $(\mathrm{OR}=5.3)$. The authors suggested that migraine with anxiety and depression may constitute a distinct syndrome comprising anxiety, often manifested in early childhood, followed by the occurrence of migraine headaches, and then by discrete episodes of depressive disorders in adulthood (Merikangas et al., 1990).

\section{Panic disorder}

A high frequency of panic disorders was noted in patients with migraine (Breslau et al., 1991) and vise versa (Stewart et al., 1989, 1994; Marazziti et al., 1999). A population-based study evaluated the temporal relation of migraine and panic disorder (Breslau et al., 2001). In the study, the life-time prevalence of panic disorder was not only higher in subjects with migraine, but also in those with other severe headaches (compared to controls). In addition, 
the onset of panic disorder was significantly higher in subjects with migraine or severe headache (HR: 3.55 vs. 5.75, respectively). The onset of migraine or severe headache was also more frequent in subjects with panic disorder (HR: 2.10 vs. 1.85, respectively). The study indicates a higher frequency of panic disorder was not specifically in migraine patients but also in other severe headache patients. A bidirectional temporal relationship was found between headache and panic disorder with a stronger direction of headache to panic disorder (Breslau et al., 2001).

\section{Bipolar disorders}

The number of studies focusing on the relationship between migraine and bipolar disorders were much less than those for anxiety and depression. Most of them were clinic-based (Younes et al., 1986; Mahmood et al., 1999; Low et al., 2003). Two populationbased studies reported the positive association between migraine and bipolar disorders in young adults (OR: 2.9-7.3) (Merikangas et al., 1990; Breslau et al., 1991).

\section{Suicide ideation and suicide attempt}

Breslau et al. (1991) and Breslau (1992) first reported that a history of migraine with aura was associated with increased frequencies of suicidal ideation and suicide attempts in young adults. One of our community-based studies in Taiwan showed young adolescents with $\mathrm{CDH}$ had a high frequency of psychiatric comorbidity (around 50\%). In addition, 20\% of adolescents with CDH had a high suicide risk (Wang et al., 2007). This association was demonstrated in subjects with migraine with aura, but not in those with migraine without aura. In our epidemiological study on young adolescents aged 13-15, migraine with aura (adjusted OR 1.79) and high headache frequency ( $>7$ days/month) (adjusted OR 1.69) were both associated with suicidal ideation (Wang et al., 2009).

\section{RESTLESS LEGS SYNDROME (RLS)}

Restless legs syndrome is a common sensorimotor disorder, and has long been considered related to dopaminergic system dysfunction. A higher prevalence of RLS (17.3-34 \%) in patients with migraine was reported in several studies (Young et al., 2003; Rhode et al., 2007; d'Onofrio et al., 2008). Our clinic-based study, recruiting 1,041 patients with primary headache disorders, showed the frequencies of RLS were higher in patients with migraine (11.4\%) than those with tension-type headache $(4.6 \%)$ or cluster headache (2.0\%) (Chen et al., 2010). Migraine patients who also had RLS were more likely to have photophobia, phonophobia, exacerbation due to physical activities, vertigo, dizziness, tinnitus, and neck pain. They were also more likely to report disability, depression, and poor sleep quality. The origin of the comorbidity of RLS in migraine patients remains unclear. We suggest a shared dopaminergic dysfunction in the A11 nucleus as an explanation for the association (Chen et al., 2010).

\section{OBESITY}

The relationship between migraine and obesity remains uncertain. In two population-based studies, BMI was not associated with the prevalence of episodic migraine (Bigal et al., 2006; Winter et al., 2009). In addition, BMI was reported to be associated with migraine frequency and chronification (Bigal et al., 2006, 2007a; Winter et al.,
2009). However, two other epidemiological studies found a positive association between migraine and increased BMI (Ford et al., 2008; Peterlin et al., 2010). It is noteworthy that the two positive studies used direct measurement of BMI; whereas, the two negative studies adopted self-report BMI values.

\section{EPILEPSY}

The association between migraine and epilepsy is still controversial. In some studies, a higher prevalence of migraine was noted in epilepsy patients, but some studies reported differently (Marks and Ehrenberg, 1993; Lipton et al., 1994; Karaali-Savrun et al., 2002; Nuyen et al., 2006). The prior studies suggest a shared genetic link between epilepsy and migraine (Baykan et al., 2004; Deprez et al., 2007; Tikka-Kleemola et al., 2010). Migraine had been reported in one family with adult onset myoclonic epilepsy (Saka and Saygi, 2000) and in one family with autosomal recessive idiopathic epilepsy (Baykan et al., 2004). A linkage analysis in a large Belgian family with occipitotemporal lobe epilepsy associated with migraine with visual aura provided evidence for a novel epilepsy and migraine susceptibility locus on chromosome 9q21-q22 (Deprez et al., 2007). A genome-wide linkage study in 36 Finnish families with at least 2 family members having scintillating scotoma revealed the same locus for visual aura (Tikka-Kleemola et al., 2010). Intriguingly, one of the genes in this region, $\mathrm{SCH} 3$, is highly expressed in occipital and temporal lobes, and regulates the neuronal adaptation against environmental stress (Troglio et al., 2004).

\section{CHRONIC PAIN DISORDERS}

Several chronic pain disorders were reported to be associated with migraine. The Nord-Trøndelag Health Study (Hagen et al., 2002) noted that subjects with headache reported more musculoskeletal pain than those without. The risk was similar between migraine and non-migraine headache patients $(\mathrm{OR}=1.9$ vs. 1.8$)$. However, headache frequency was a strong predictor for musculoskeletal pain. Von Korff et al. (2005) also found that patients with selfreported chronic spine pain were associated with migraine with an OR of 5.2. Fibromyalgia was very common in patients with migraine with frequencies between 22 and 40\%. (Peres et al., 2001; Ifergane et al., 2006; de Tommaso et al., 2009) The development of fibromyalgia was highly associated with migraine frequency. Patients who suffered from both migraine and fibromyalgia reported a higher prevalence of insomnia, lower quality of life and more mental stress (Peres et al., 2001; de Tommaso et al., 2009). It is interesting that the fibromyalgia was more frequent in female migraine patients than male patients (Ifergane et al., 2006; de Tommaso et al., 2009).

\section{OTHER COMORBID DISORDERS}

Regarding asthma, one large epidemiological study (Head-Hunt study) performed in Norway reported that both migraine and non-migrainous headaches were related to asthma and chronic bronchitis (Aamodt et al., 2007). Of note, the association was more related to headache frequencies than headache diagnoses (Aamodt et al., 2007). But, in another study, the incidence of newly diagnosed asthma was not different between subjects with and without migraine (OR 1.17) (Becker et al., 2008). The association between 
migraine and irritable bowel disease was also noted in some clinical and epidemiological studies (Azpiroz et al., 2000; Vandvik et al., 2004; Mulak and Paradowski, 2005; Cole et al., 2006). Based on a dataset of a national US health care plan, patients with irritable bowel syndrome had a higher OR (1.6) to have migraine, compared with those without (Cole et al., 2006). High frequency of celiac disease was also noted in migraine patients (Gabrielli et al., 2003; Alehan et al., 2008). In addition, one hospital-based study reported a high migraine frequency ( $12.6 \%$ vs. $5.7 \%)$ in children and young adults with celiac disease (Zelnik et al., 2004). These results support the conclusion that celiac disease was one comorbid disorder of migraine. Furthermore, chronic fatigue syndrome (Peres et al., 2002; Tietjen et al., 2010), Raynaud's phenomenon, systemic lupus erythematosus (Mizutani et al., 1985; Terwindt et al., 1998; Glanz et al., 2001; Weder-Cisneros et al., 2004) and narcolepsy (Dahmen et al. 1999, 2003; DMKG study group, 2003) were also reported to be associated with migraine in hospital-based studies.

\section{DISCUSSION}

The pathophysiology of the link between migraine and comorbid disorders is uncertain. Several possibilities have been proposed.

\section{POSSIBLE SHARED MECHANISMS BETWEEN MIGRAINE WITH AURA AND CVD}

First, subjects with migraine with aura may have other traditional cardiovascular risk factors, which increase the risk of vascular diseases, such as higher total cholesterol, lower high-density lipoprotein cholesterol (HDL), higher total cholesterol-to-HDL ratios and higher blood pressure (Scher et al., 2005b). Second, the proinflammatory or vasoactive peptide released during migraine attacks may damage the vascular endothelium and result in stroke or other vascular events (Kurth et al., 2006; Tietjen, 2007). Third, lower levels of endothelial progenitor cells in migraineurs indicated a reduced endothelial repair capacity, particularly in migraine with aura, which may contribute to the association between migraine and vascular diseases (Elkind, 2008; Lee et al., 2008). Fourth, the genetic risk factors are possible shared mechanisms between migraine and cardiovascular diseases (Scher et al., 2006; Schürks et al., 2008). The ACE DD genotype was reported to act in combination with the MTHFR T/T genotype to increase migraine susceptibility, with the greatest effect in those with aura (Lea et al., 2005).

\section{POSSIBLE SHARED MECHANISMS BETWEEN MIGRAINE AND PSYCHIATRIC DISORDERS}

The proposed mechanism is the shared serotonergic dysfunction between migraine and affective disorders (Hamel, 2007). Plasma level of serotonin was decreased between migraine attacks and increased during migraine attacks (Ferrari and Saxena, 1993). Second, migraine and depression were 2-3 times more common in women than in men, with a similar monthly fluctuation (Kessler et al., 1994; Lipton et al., 2001). As the ovarian hormones change, particularly the estrogen decline, they may induce down-regulation of the serotonergic system and up-regulation of the sympathetic system, and result in the co-existence of migraine and affective problems (Martin and Behbehani, 2006). Third, dysregulation of the hypothalamic pituitary adrenal (HPA) axis was noted in both depression and migraine (Peres et al., 2001; Barden, 2004). It is hypothesized that activation of the HPA axis with reduced serotonin synthesis may be the link between affective disorders, migraine and obesity (Bigal et al., 2007b).

\section{TREATMENT IMPLICATIONS OF COMORBIDITIES}

The comorbidities should be considered when choosing acute and prophylactic agents for migraine treatment. Since migraine with aura is a well documented risk factor for CVD, conventional cardiovascular risk factors should be strictly controlled in these patients, including blood pressure control, smoking cessation and avoidance of oral contraceptive agents (Bousser et al., 2000). In migraine patients who already have CVD, ergotamines, triptans and COX-2 inhibitors should be avoided as acute abortive treatment. In addition, tricyclic antidepressants (TCAs) should be used with caution because of the risk to cause cardiac conduction abnormality. In migraine patients with depression, TCAs and selective norepinephrine re-uptake inhibitor (SNRI) are good choices for prevention, but flunarizine and beta-blockers should be avoided, particularly in the elderly because of the risk of exacerbation of depression. Of note, flunarizine is widely used in Europe and Asia, but not available in the United States. In addition, neuroleptics, selective serotonin reuptake inhibitors (SSRIs), SNRI, mirtazepine and flunarizine should be avoided in migraine patients with RLS. If migraine patients have comorbidities like epilepsy or bipolar disorder, anticonvulsants should be considered in a preventive treatment regimen.

\section{FUTURE DIRECTIONS FOR RESEARCH}

Large cohort studies are still needed to delineate and confirm the relationship between migraine and its comorbid diseases. Strict criteria for the diagnoses of migraine and aura should be implemented. The frequency and associated symptoms should also be recorded in detail. The comorbidities, such as cardiovascular disease, depression or RLS, should also be diagnosed with clear definitions, and the well known risk factors for these comorbid disorders need to be controlled. Furthermore, genetic and biological researches are important to investigate the shared pathophysiological mechanisms.

\section{CONCLUSION}

Comorbidities may emerge from population-based studies as well as clinical series or case-control studies. Results from the latter two designs must be taken into account with caution, due to the possible introduction of Berkson's bias or other selection bias (Bonavita and De Simone, 2008). Patients with migraine, especially migraine with aura, are at an increased risk of CVD and psychiatric disorders. Women with migraine seem to have a higher risk of CVD, compared to men. The association of migraine and depression and panic disorder is bidirectional. Young adults or adolescents with migraine with aura have a higher suicide risk. New data on comorbid RLS, epilepsy, obesity and asthma are emerging. Understanding the association of migraine with comorbid health conditions is important in providing optimal care, as well as helping understand the underlying mechanisms of migraine.

\section{ACKNOWLEDGMENT}

This review was supported in part by Taipei Veterans General Hospital (V99C1-063) and Ministry of Education (Aim for the Top University Plan). 


\section{REFERENCES}

Aamodt,A.H., Stovner,L. J., Langhammer, A., Hagen, K., and Zwart, J. A. (2007). Is headache related to asthma, hay fever, and chronic bronchitis? The Head-HUNT Study. Headache 47, 204-212.

Alehan, F., Ozçay, F., Erol, I., Canan, O., and Cemil, T. (2008). Increased risk for coeliac disease in paediatric patients with migraine. Cephalalgia 28, 945-949.

Andlin-Sobocki, P., Jönsson, B., Wittchen, H. U., and Olesen, J. (2005). Cost of disorders of the brain in Europe. Eur. J. Neurol. 12, 1-27.

Anzola, G. P., Magoni, M. D., Guindani, M., Rozzini, L., and Dalla Volta, G. D. (1999). Potential source of cerebral embolism in migraine with aura. A transcranial Doppler study. Neurology 52, 1622-1625.

Azpiroz, F., Dapoigny, M., Pace, F., MüllerLissner, S., Coremans, G., Whorwell, P., Stockbrugger, R. W., and Smout, A. (2000). Nongastrointestinal disorders in the irritable bowel syndrome. Digestion 62, 66-72.

Barden, N. (2004). Implication of the hypothalamic-pituitary-adrenal axis in the physiopathology of depression. J. Psychiatry Neurosci. 29, 185-193.

Baykan, B., Madia, F., Bebek, N., Gianotti, S., Güney, A. I., Cine, N., Bianchi, A., Gökyiğit, A., and Zara, F. (2004). Autosomal recessive idiopathic epilepsy in an inbred family from Turkey: identification of a putative locus on chromosome 9q32-33. Epilepsia 45, 479-487.

Becker, C., Brobert, G. P., Almqvist, P. M., Johansson, S., Jick, S. S., and Meier, C. R. (2008). The risk of newly diagnosed asthma in migraineurs with or without previous triptan prescriptions. Headache 48, 606-610.

Bigal, M. E., Kurth, T., Santanello, N., Buse, D., Golden, W., Robbins, M., and Lipton, R. B. (2010). Migraine and cardiovascular disease: a populationbased study. Neurology 74, 628-635.

Bigal, M. E., Liberman, J. N., and Lipton, R. B. (2006). Obesity and migraine: a population study. Neurology 66, 545-550.

Bigal, M. E., Tsang, A., Loder, E., Serrano, D., Reed, M. L., and Lipton, R. B. (2007a). Body mass index and episodic headaches: a population-based study. Arch. Intern. Med. 167, 1964-1970.

Bigal, M. E., and Lipton, R. B., Holland, P. R., and Goadsby, P.J. (2007b). Obesity, migraine and chronic migraine: possible mechanisms of interaction. Neurology 68, 1851-1861.

Bonavita, V., and De Simone, R. (2008). Towards a definition of comorbidity in the light of clinical complexity. Neurol. Sci. 29, S99-S102.
Bousser, M. G., Conard, J., Kittner, S., de Lignières, B., MacGregor, E. A., Massiou, H., Silberstein, S. D., and Tzourio, C. (2000). Recommendations on the risk of ischaemic stroke associated with use of combined oral contraceptives and hormone replacement therapy in women with migraine. The International Headache Society Task Force on Combined Oral Contraceptives \& Hormone Replacement Therapy. Cephalalgia 20, 155-156.

Breslau, N. (1992). Migraine, suicidal ideation, and suicide attempts. Neurology 42, 392-395.

Breslau, N., Davis, G. C., and Andreski, P. (1991). Migraine, psychiatric disorders, and suicide attempts: an epidemiologic study of young adults. Psychiatry Res 37, 11-23.

Breslau, N., Davis, G. C., Schultz, L. R. and Peterson, E. L. (1994). Migraine and major depression: A longitudinal study. Headache 34, 387-393.

Breslau, N., Lipton, R. B., Stewart, W. F., Schultz, L. R., and Welch, K. M. (2003). Comorbidity of migraine and depression: investigating potential etiology and prognosis. Neurology 60, 1308-1312.

Breslau, N., Schultz, L. R., Stewart, W. F, Lipton, R. B., Lucia, V. C., and Welch, K. M. A. (2000). Headache and major depression: Is the association specific to migraine? Neurology 54, 308-313.

Breslau, N., Schultz, L. R., Stewart, W. F., Lipton, R. B., and Welch, K. M. A. (2001). Headache types and panic disorder. Neurology 56, 350-354.

Buzzi, M.G., and Moskowitz, M.A. (2005) The pathophysiology of migraine: year 2005. J. Headache Pain 6, 105-111.

Carod-Artal, F. J., da Silveira Ribeiro, L., Braga, H., Kummer, W., Mesquita, H. M., and Vargas, A. P. (2006). Prevalence of patent foramen ovale in migraine patients with and without aura compared with stroke patients. A transcranial Doppler study. Cephalalgia 26, 934-939.

Chen, P. K., Fuh, J. L., Chen, S. P., and Wang, S.J. (2010).Association between restless legs syndrome and migraine. J. Neurol. Neurosurg. Psychiatr. 81, 524-528.

Cirillo, M., Stellato, D., Lombardi, C., De Santo, N. G., and Covelli, V. (1999). Headache and cardiovascular risk factors: positive association with hypertension. Headache 39, 409-416.

Cole, J. A., Rothman, K. J., Cabral, H. J., Zhang, Y., and Farraye, F. A. (2006). Migraine, fibromyalgia, and depression among people with IBS: a prevalence study. BMC Gastroenterol. 6, 26.

Dahmen, N., Kasten, M., Wieczorek, S., Gencik, M., Epplen, J. T., and Ullrich,
B. (2003). Increased frequency of migraine in narcoleptic patients: a confirmatory study. Cephalalgia 23 , 14-19.

Dahmen, N., Querings, K., Grün, B., and Bierbrauer, J. (1999). Increased frequency of migraine in narcoleptic patients. Neurology 52, 1291-1293.

Del Sette, M., Angeli, S., Leandri, M., Ferriero, G., Bruzzone, G. L. Finocchi, C., and Gandolfo, C. (1998). Migraine with aura and right-to-left shunt on transcranial Doppler: a case-control study. Cerebrovasc. Dis. 8, 327-330.

Deprez, L., Peeters, K., Van Paesschen, W., Claeys, K. G,, Claes, L. R., Suls, A. Audenaert, D., Van Dyck, T., Goossens, D., Del-Favero, J., and De Jonghe, P. (2007). Familial occipitotemporal lobe epilepsy and migraine with visual aura: linkage to chromosome 9q. Neurology 68, 1995-2002.

de Tommaso, M., Sardaro, M., Serpino, C. Costantini, F., Vecchio, E., Prudenzano, M. P., Lamberti, P., and Livrea, P. (2009). Fibromyalgia comorbidity in primary headaches. Cephalalgia 29, 453-464.

DMKGStudy Group.(2003).Migraineand idiopathic narcolepsy-a case-control study. Cephalalgia 23, 786-789.

d'Onofrio, F., Bussone, G., Cologno, D. Petretta, V., Buzzi, M. G., Tedeschi, G. Bonavita, V., and Cicarelli, G. (2008) Restless legs syndrome and primary headaches: a clinical study. Neurol. Sci. 29(Suppl. 1), S169-S172.

Dowson, A., Mullen, M. J., Peatfield, R., Muir, K., Khan, A. A., Wells, C., Lipscombe, S. L., Rees, T., De Giovanni, J. V., Morrison, W. L. Hildick-Smith, D., Elrington, G. Hillis, W. S., Malik, I. S., and Rickards, A. (2008). Migraine Intervention With STARFlex Technology (MIST) trial: a prospective, multicenter, doubleblind, sham-controlled trial to evaluate the effectiveness of patent foramen ovale closure with STARFlex septal repair implant to resolve refractory migraine headache. Circulation 117 1397-1404.

Elkind, M. S. (2008). Endothelial repair capacity and migraine: the fix is in Neurology 70, 1506-1507.

Ferrari, M.D., and Saxena, P.R. (1993). On serotonin and migraine: a clinical and pharmacological review. Cephalalgia 13, 151-165.

Ferrarini, G., Malferrari, G., Zucco, R., Gaddi, O., Norina, M., and Pini, L. A. (2005). High prevalence of patent foramen ovale in migraine with aura. J. Headache Pain 6, 71-76.

Ford, E. S., Li, C., Pearson, W. S., Zhao, G., Strine, T. W., and Mokdad, A. H. (2008). Body mass index and headaches: findings from a national sample of US adults. Cephalalgia 28 1270-1276.

Franceschi, M., Colombo, B., Rossi, P., and Canal, N. (1997). Headache in a population-based elderly cohort. An ancillary study to the Italian Longitudinal Study of Aging (ILSA). Headache 37, 79-82.

Gabrielli, M., Cremonini, F., Fiore, G., Addolorato, G., Padalino, C., Candelli, M., De Leo, M. E., Santarelli, L. Giacovazzo, M., Gasbarrini,A., Pola, P., and Gasbarrini,A. (2003). Association between migraine and Celiac disease: results from a preliminary casecontrol and therapeutic study. Am. J. Gastroenterol. 98, 625-629.

Glanz, B. I., Venkatesan, A., Schur, P. H. Lew, R. A., and Khoshbin, S. (2001). Prevalence of migraine in patients with systemic lupus erythematosus. Headache 41, 285-289.

Hagen, K., Einarsen, C., Zwart, J. A., Svebak, S., and Bovim, G. (2002). The co-occurrence of headache and musculoskeletal symptoms amongst 51,050 adults in Norway. Eur. J. Neurol. 9, 527-533.

Hamel, E. (2007). Serotonin and migraine: biology and clinical implications. Cephalalgia 27, 1293-1300.

Ifergane, G., Buskila, D., Simiseshvely, N., Zeev, K., and Cohen, H. (2006). Prevalence of fibromyalgia syndrome in migraine patients. Cephalalgia 26 451-456.

Jesurum, J. T., Fuller, C. J., Kim, C. J., Krabill, K. A., Spencer, M. P., Olsen, J. V., Likosky, W. H., and Reisman, M. (2008). Frequency of migraine headache relief following patent foramen ovale "closure" despite residual rightto-left shunt. Am. J. Cardiol. 102, 916-920.

Juang, K. D., Wang, S. J., Fuh, J. L., Lu, S. R., and Su, T. O. (2000). Comorbidity of depressive and anxiety disorders in chronic daily headache and its subtypes. Headache 40, 818-823.

Karaali-Savrun, F., Göksan, B., Yeni, S. N., Ertan, S., and Uzun, N. (2002). Seizure-related headache in patients with epilepsy. Seizure 11, 67-69.

Kessler, R. C., McGonagle, K. A., Zhao, S. Nelson, C. B., Hughes, M., Eshleman, S., Wittchen, H. U., and Kendler, K. S. (1994). Lifetime and 12-month prevalence of DSM-III-R psychiatric disorders in the United States. Results from the National Comorbidity Survey. Arch. Gen. Psychiatry 51, 8-19.

Kruit, M. C., Launer, L. J., Ferrari, M. D., and van Buchem, M.A. (2005). Infarcts in the posterior circulation territory in migraine. The population-based MRI CAMERA study. Brain 128, 2068-2077.

Kruit, M.C., van Buchem, M.A., Hofman, P. A., Bakkers, J. T., Terwindt, G. M., 
Ferrari, M. D., and Launer, L. J. (2004). Migraine as a risk factor for subclinical brain lesions. JAMA 291, 427-434.

Kurth, T., Gaziano. J. M., Cook, N., Bubes, V., Logroscino, G., Diener, H. C., and Buring, J. E. (2007). Migraine and risk of cardiovascular disease in men. Arch. Intern. Med. 167, 795-801.

Kurth, T., Gaziano, J. M., Cook, N. R., Logroscino, G., Diener, H. C., and Buring, J.E. (2006). Migraine and risk of cardiovascular disease in women. JAMA 296, 283-291.

Kurth, T., Schürks, M., Logroscino, G., Gaziano, J. M., and Buring, J.E. (2008). Migraine, vascular risk, and cardiovascular events in women: prospective cohort study. BMJ 337, a636.

Kurth, T., Slomke, M. A., Kase, C. S., Cook, N. R., Lee, I. M., Gaziano, J. M., Diener, H. C., and Buring, J. E. (2005). Migraine, headache, and the risk of stroke in women: a prospective study. Neurology 64, 1020-1026.

Lea, R. A., Ovcaric, M., Sundholm, J., Solyom, L., Macmillan, J., and Griffiths, L. R. (2005). Genetic variants of angiotensin converting enzyme and methylenetetrahydrofolate reductase may act in combination to increase migraine susceptibility. Brain Res. Mol. Brain Res. 136, 112-1177.

Lee, S. T., Chu, K., Jung, K. H., Kim, D. H., Kim, E. H., Choe, V. N., Kim, J.H., Im, W. S., Kang, L., Park, J. E., Park, H. J., Park, H. K., Song, E. C., Lee, S. K., Kim, M., and Roh, J. K. (2008). Decreased number and function of endothelial progenitor cells in patients with migraine. Neurology 70, 1510-1517.

Lipton, R. B., Ottman, R., Ehrenberg, B. L., and Hauser, W.A. (1994).Comorbidity of migraine: the connection between migraine and epilepsy. Neurology 44(10 Suppl. 7), S28-S32.

Lipton, R. B., and Silberstein, S. D. (1994). Why study the comorbidity of migraine? Neurology 44(10 Suppl. 7), S4-S5.

Lipton, R. B., Stewart, W. F., Diamond, S., Diamond, M. L., and Reed, M. (2001). Prevalence and burden of migraine in the United States: data from the American Migraine Study II. Headache 41, 646-657.

Low, N.C., DuFort, G. G., and Cervantes, P. (2003). Prevalence, clinical correlates, and treatment of migraine in bipolar disorder. Headache 43, 940-949.

Lu, S. R., Fuh, J. L., Chen, W. T., Juang, K. D., and Wang, S. J. (2001). Chronic daily headache in Taipei, Taiwan: prevalence, follow-up and outcome predictors. Cephalalgia 21, 980-986.

Lu, S. R., Fuh, J. L., Juang, K. D., and Wang, S. J. (2000). Repetitive intravenous prochlorperazine treatment of patients with refractory chronic daily headache. Headache 40, 724-729.

Mahmood, T., Romans, S., and Silverstone, T. (1999). Prevalence of migraine in bipolar disorder. J. Affect. Disord. 52, 239-241.

Marazziti, D., Toni, C., Pedri, S., Bonuccelli, U., Pavese, N., Lucetti, C., Nuti, A., Muratorio, A., and Cassano, G. B. (1999). Prevalence of headache syndromes in panic disorder. Int. Clin. Psychopharmacol. 14, 247-251.

Marks, D. A., and Ehrenberg, B. L. (1993). Migraine-related seizures in adults with epilepsy, with EEG correlation. Neurology 43, 2476-2483.

Martin, V. T., and Behbehani, M. (2006). Ovarian hormones and migraine headache: understanding mechanisms and pathogenesis-part I. Headache 46, 3-23.

McWilliams, L. A., Goodwin, R. D., and Cox, B. J. (2004). Depression and anxiety associated with three pain conditions: results from a nationally representative sample. Pain 111, 77-83.

Merikangas, K. R., Angst, J., and Isler, H. (1990). Migraine and psychopathology. Results of the Zurich cohort study of young adults. Arch. Gen. Psychiatry 47, 849-853.

Mizutani, W. T., Hutchinson, M., and Ouismorio, F. P. (1985). Association of migraine headache and Raynaud's phenomenom in systemic lupus erythematosus. Arthritis Rheum. 28, S63.

Mulak, A., and Paradowski, L. (2005). Migraine and irritable bowel syndrome. Neurol. Neurochir. Pol. 39, S55-S60.

Nuyen, J., Schellevis, F. G., Satariano, W.A., Spreeuwenberg, P. M., Birkner, M. D., van den Bos, G. A., and Groenewegen, P. P. (2006). Comorbidity was associated with neurologic and psychiatric diseases: a general practice-based controlled study. J. Clin. Epidemiol. $59,1274-1284$.

Peres, M.F., Sanchez del Rio, M.,Seabra,M. L., Tufik, S., Abucham, J., Cipolla-Neto, J., Silberstein, S. D., and Zukerman, E. (2001). Hypothalamic involvement in chronic migraine. J. Neurol. Neurosurg. Psychiatr. 71, 747-751.

Peres, M. F., Young, W. B., Kaup, A. O., Zukerman, E., and Silberstein, S. D. (2001). Fibromyalgia is common in patients with transformed migraine. Neurology 57, 1326-1328.

Peres, M. F., Zukerman, E., Young, W. B., and Silberstein, S. D. (2002). Fatigue in chronic migraine patients. Cephalalgia 22, 720-724.

Peterlin, B. L., Rosso, A. L., Rapoport, A. M., and Scher, A. I. (2010). Obesity and migraine: the effect of age, gender and adipose tissue distribution. Headache 50, 52-62.
Post, M., Thijs, V., Herroelen, L., and Budts, W. (2004). Closure of patent ovale is associated with decrease in prevalence of migraine. Neurology 62, 1439-1440.

Rasmussen, B. K., and Olesen, J. (1992). Symptomatic and nonsymptomatic headaches in a general population. Neurology 42, 1225-1231.

Rhode, A. M., Hösing, V. G., Happe, S., Biehl, K., Young, P., and Evers, S. (2007). Comorbidity of migraine and restless legs syndrome-a case-control study. Cephalalgia 27, 1255-1260.

Rose, K. M., Carson, A. P., Sanford, C. P. Stang, P. E., Brown, C. A., Folsom, A. R., and Szklo, M. (2004). Migraine and other headaches: associations with Rose angina and coronary heart disease. Neurology 63, 2233-2239.

Rundek, T., Elkind, M. S., Di Tullio, M. R., Carrera, E., Jin, Z., Sacco, R. L., and Homma, S. (2008). Patent foramen ovale and migraine: a cross-sectional study from the Northern Manhattan Study (NOMAS). Circulation 118, 1419-1424.

Saka, E., and Saygi, S. (2000). Familial adult onset myoclonic epilepsy associated with migraine. Seizure 9 , 344-346.

Scher, A. I., Bigal, M. E., and Lipton, R. B. (2005a). Comorbidity of migraine. Curr. Opin. Neurol. 18, 305-310.

Scher, A. I., Terwindt, G. M., Picavet, H.S., Verschuren, W. M., Ferrari, M. D., and Launer, L. J. (2005b). Cardiovascular risk factors and migraine: the GEM population-based study. Neurology 64, 614-620.

Scher, A. I., Gudmundsson, L. S., Sigurdsson, S., Ghambaryan, A., Aspelund, T., Eiriksdottir, G., van Buchem, M. A., Gudnason, V., and Launer, L. J. (2009). Migraine headache in middle age and late-life brain infarcts. JAMA 301, 2563-2570.

Scher, A. I., Terwindt, G. M., Verschuren, W.M., Kruit, M. C., Blom, H. J., Kowa, H., Frants, R. R., van den Maagdenberg, A. M., van Buchem, M., Ferrari, M. D. and Launer, L. J. (2006). Migraine and MTHFR C677T genotype in a populationbased sample. Ann. Neurol. 59, 372-375.

Schürks, M., Zee, R. Y., Buring, J. E., and Kurth, T. (2008). Interrelationships among the MTHFR $677 \mathrm{C}>\mathrm{T}$ polymorphism, migraine, and cardiovascular disease. Neurology 71 , 505-513.

Schürks, M., Zee, R. Y., Buring, J. E., and Kurth, T. (2009). ACE D/I polymorphism, migraine, and cardiovascular disease in women. Neurology 72 650-656.

Schwedt, T. J., Demaerschalk, B. M., and Dodick, D. W. (2008). Patent foramen ovale and migraine: a quantitative systematic review. Cephalalgia 28, 531-540.

Schwedt, T. J., and Dodick, D. W. (2006). Patent foramen ovale and migraine: bringing closure to the subject. Headache 46, 663-671.

Schwerzmann, M., Nedeltchev, K., Lagger, F., Mattle, H. P., Windecker, S., Meier, B., and Seiler, C. (2005). Prevalence and size of directly detected patent foramen ovale in migraine with aura. Neurology 65, 1415-1418.

Schwerzmann, M., Wiher, S., Nedeltchev, K., Mattle, H. P., Wahl, A., and Seiler, C. (2004). Percutaneous closure of patent foramen ovale reduces the frequency of migraine attacks. Neurology 62, $1399-1401$.

Smoller, J.W., Pollack, M. H., WassertheilSmoller, S., Barton, B., Hendrix, S. L., Jackson, R. D., Dicken, T., Oberman, A., and Sheps, D. S. (2003). Women's Health Initiative Investigators. Prevalence and correlates of panic attacks in postmenopausal women: Results from an ancillary study to the Women's Health Initiative. Arch. Intern. Med. 163, 2041-2050.

Stang, P. E., Carson, A. P., Rose, K. M., Mo, J., Ephross, S. A., Shahar, E., and Szklo, M. (2005). Headache, cerebrovascular symptoms, and stroke: the Atherosclerosis Risk in Communities Study. Neurology 64, 1573-1577.

Stewart, W. F., Breslau, N., and Keck, P. E. Jr. (1994). Comorbidity of migraine and panic disorder. Neurology 44, S23-S27.

Stewart, W. F., Linet, M. S., and Celentano, D. D. (1989). Migraine headaches and panic attacks. Psychosom. Med. 51, 559-569.

Stewart, W. F., Lipton, R. B., Celentano, D. D., and Reed, M. L. (1992). Prevalence of migraine headache in the United States: relation to age, income, race and other sociodemographic factors. JAMA 267, 64-69.

Terwindt, G. M., Haan,. J., Ophoff, R. A., Groenen, S. M., Storimans, C. W., Lanser, J. B., Roos, R. A., BleekerWagemakers, E. M., Frants, R. R., and Ferrari, M. D. (1998). Clinical and genetic analysis of a large Dutch family with autosomal dominant vascular retinopathy, migraine and Raynaud's phenomenon. Brain 121, 303-316.

Tietjen, E. G. (2007). Migraine and ischaemic heart disease and stroke: potential mechanisms and treatment implications. Cephalalgia 27, 981-987.

Tietjen, G. E., Brandes, J. L., Digre, K. B., Baggaley, S., Martin, V., Recober, A., Geweke, L. O., Hafeez, F., Aurora, S. K., Herial, N. A., Utley, C., and Khuder, S. A. (2007). High prevalence of somatic symptoms and depression in women 
with disabling chronic headache. Neurology 68, 134-140.

Tietjen, G. E., Brandes, J. L., Peterlin, B. L., Eloff, A., Dafer, R. M., Stein, M. R., Drexler, E., Martin, V. T., Hutchinson, S., Aurora, S. K., Recober, A., Herial, N. A., Utley, C., White, L., and Khuder, S. A. (2010). Childhood maltreatment and migraine (part III). Association with comorbid pain conditions. Headache 50, 42-51.

Tikka-Kleemola, P., Artto, V., Vepsäläinen, S., Sobel, E. M., Räty, S., Kaunisto, M. A., Anttila, V., Hämäläinen, E., Sumelahti, M. L., Ilmavirta, M., Färkkilä, M., Kallela, M., Palotie, A., and Wessman, M. (2010). A visual migraine aura locus maps to 9q21-q22. Neurology 74, 1171-1177.

Troglio, F., Echart, C., Gobbi, A., Pawson, T., Pelicci, P. G., De Simoni, M. G., and Pelicci, G. (2004). The Rai (Shc C) adaptor protein regulates the neuronal stress response and protects against cerebral ischemia. Proc. Natl. Acad. Sci. U.S.A. 101, $15476-15481$.

Tzourio, C., Gagnière, B., El Amrani, M., Alpérovitch, A., and Bousser, M. G. (2003). Relationship between migraine, blood pressure and carotid thickness. A population-based study in the elderly. Cephalalgia 23, 914-920.

Vandvik, P.O., Wilhelmsen, I., Ihlebaek, C., and Farup, P. G. (2004). Comorbidity of irritable bowel syndrome in general practice: a striking feature with clinical implications. Aliment. Pharmacol. Ther. 20, 1195-1203.

Von Korff, M., Crane, P., Lane, M., Miglioretti, D. L., Simon, G., Saunders, K., Stang, P., Brandenburg, N., and Kessler, R. (2005). Chronic spinal pain and physical-mental comorbidity in the United States: results from the national comorbidity survey replication. Pain 113 , 331-339.

Wang, S. J., Fuh, J. L., Juang, K. D., and Lu, S. R. (2009). Migraine and suicidal ideation in adolescents aged 13 to 15 years old. Neurology 72 , 1146-1152.

Wang, S. J., Fuh, J. L., Lu, S. R., and Juang, K. D. (2001). Quality of life differs among headache diagnoses: analysis of SF-36 survey in 901 headache patients. Pain 89, 285-292.

Wang, S. J., Fuh, J. L., Young, Y. H., Lu, S. R., and Shia, B. C. (2000). Prevalence of migraine in Taipei, Taiwan: a population-based survey. Cephalalgia 20, 566-572.
Wang, S. J., Juang, K. D., Fuh, J. L., and Lu, S. R. (2007). Psychiatric comorbidity and suicide risk in adolescents with chronic daily headache. Neurology 68, 1468-1473.

Weder-Cisneros, N. D., Téllez-Zenteno, J. F., Cardiel, M. H., Guibert-Toledano, M., Cabiedes, J., Velásquez-Paz, A. L., García-Ramos, G., and Cantú, C. (2004). Prevalence and factors associated with headache in patients with systemic lupus erythematosus. Cephalalgia 24, 1031-1044.

Wiehe, M., Fuchs, S. C., Moreira, L. B., Moraes, R. S., and Fuchs, F. D. (2002). Migraine is more frequent in individuals with optimal and normal blood pressure: a population-based study. $J$. Hypertens. 20, 1303-1306.

Winter, A. C., Berger, K., Buring, J. E., and Kurth, T. (2009). Body mass index, migraine, migraine frequency and migraine features in women. Cephalalgia 29, 269-278.

Younes, R. P., De Long, G. R., Neiman, G., and Rosner, B. (1986). Manicdepressive illness in children: Treatment with lithium carbonate. J. Child Neurol. 1, 364-368.

Young, W. B., Piovesan, E. J., and Biglan, K. M. (2003). Restless legs syndrome and drug-induced akathisia in headache patients. CNS Spectr. 8, 450-456.

Zelnik, N., Pacht, A., Obeid, R., and Lerner, A. (2004). Range of neurologic disorders in patients with celiac disease. Pediatrics 113, 1672-1676.

Conflict of Interest Statement: The authors declare that the research was conducted in the absence of any commercial or financial relationships that could be construed as a potential conflict of interest.

Received: 05 March 2010; paper pending published: 29 April 2010; accepted: 28 June 2010; published online: 23 August 2010.

Citation: Wang S-J, Chen P-K and Fuh $J-L$ (2010) Comorbidities of migraine. Front. Neur. 1:16. doi: 10.3389/ fneur.2010.00016

This article was submitted to Frontiers in Headache Medicine and Facial Pain, a specialty of Frontiers in Neurology.

Copyright $\odot 2010$ Wang, Chen and Fuh. This is an open-access article subject to an exclusive license agreement between the authors and the Frontiers Research Foundation, which permits unrestricted use, distribution, and reproduction in any medium, provided the original authors and source are credited. 